\title{
Seismic reflections from the crystalline crust below the Continental Deep Drilling Site KTB: Modeling and inference on reflector properties
}

\author{
M. Zillmer ${ }^{1}$ and G. Müller \\ Institute of Meteorology and Geophysics, J. W. Goethe University, Frankfurt am Main, Germany \\ M. Stiller \\ Geoforschungszentrum Potsdam, Potsdam, Germany \\ Received 31 July 2001; revised 9 March 2002; accepted 14 March 2002; published 10 September 2002.
}

[1] The three-dimensional (3-D) reflection-seismic data set ISO-89 3D was recorded near the deep borehole KTB in southeastern Germany. Reflections from the SE1 reflector and from the top of the Erbendorf body (EB) in the upper crystalline crust can be identified in $5-10 \%$ of the single-shot sections. The reflectors have been first identified in previous studies of stacked and migrated seismic data. In this paper the velocity and density variations of these two structures are estimated in a new way using true amplitude single-shot (vibroseis) data. The method uses the direct wave $P_{g}$ as a reference phase and models the amplitude ratios of the SE1 and EB reflections to $P_{g}$. Modeling in this paper uses a combination of ray theory and the reflectivity method, and the SE1 and the top of the EB are assumed to be obliquely oriented 1-D structures. $P_{g}$ modeling shows that a depth-dependent velocity function within the uppermost crystalline basement explains the amplitudes and travel times of this phase with sufficient accuracy. The largest observed amplitude ratios $\mathrm{SE} 1 / P_{g}$ and $\mathrm{EB} / P_{g}$ are explained by laminated models with strong velocity contrasts and with reflection coefficients of magnitude $0.1-0.2$ (SE1) and 0.050.15 (EB). The total thickness of the reflecting zones is less than $\sim 300 \mathrm{~m} . P_{g}$ amplitude modeling requires low $Q_{p}$ factors $(<100)$ to a depth of $\sim 1 \mathrm{~km}$, whereas at larger depths, values of several hundred are necessary to keep the SE1 and EB velocity contrasts in realistic ranges. Both reflectors can be interpreted as cataclastic zones. For the SE1 this interpretation agrees with the view that it is a steeply dipping thrust fault which continues the tectonic Franconian Lineament into the upper crust. We assume that the EB is the fractured top of a high-velocity zone at depths below $\sim 10 \mathrm{~km}$, known from earlier wide-angle measurements. Both reflectors have large weakly reflecting or nonreflecting parts. The SE1 is nonreflecting at the intersection with the KTB borehole. INDEX TERMS: 7205 Seismology: Continental crust (1242); 7203 Seismology: Body wave propagation; 0935 Exploration Geophysics: Seismic methods (3025); KEYWORDS: continental crust, three-dimensional seismic survey, body waves, borehole, KTB

Citation: Zillmer M., G. Müller, and M. Stiller, Seismic reflections from the crystalline crust below the Continental Deep Drilling Site KTB: Modeling and inference on reflector properties, J. Geophys. Res., 107(B9), 2180, doi:10.1029/2001JB000843, 2002.

\section{Introduction}

[2] The German Continental Deep Drilling Program, KTB, whose main drilling phase occurred from 1990 to 1994, was preceded by an extensive seismic survey in 1989, the ISO-89 project (Integrated Seismics Oberpfalz). The largest part of this project was a 3-D reflection survey with

\footnotetext{
${ }^{1}$ Now at GEOMAR, Research Center for Marine Geosciences, University of Kiel, Kiel, Germany.

Copyright 2002 by the American Geophysical Union. 0148-0227/02/2001JB000843\$09.00
}

the KTB at its center. The combination of borehole measurements and seismic surveys at the surface is a feature of a number of scientific deep drilling projects such as those at the Siljan impact structure in Sweden [Juhlin, 1990], at the Kola superdeep borehole in Russia [Carr et al., 1996; Ganchin et al., 1998], and at the SG4 borehole in the Urals in Russia [Juhlin et al., 1997]. The purpose of the combination is to relate the reflections, visible in the seismic data, to the physical parameters and the lithology of the rocks in the borehole, determined from logs and from drill cores and cuttings. Understanding the nature of seismic reflectors at one point provides strong support for interpretations of larger seismic data sets. Juhlin [1990], for instance, success- 
fully explained several reflections on seismic profiles across the Siljan structure by dolerite sills intersecting the borehole.

[3] The seismic measurements at KTB have a particular feature: instead of the profile coverage typical in the other projects there is areal coverage of the surface, which allows a true 3-D structural investigation. Several papers and KTB reports were devoted to presentation and first interpretations of the ISO-89 3D data [e.g., Dürbaum et al., 1990, 1992; Stiller, 1991, 1992; Wiederhold, 1992], and several reflecting structures were identified in the depth range from about 2 to $15 \mathrm{~km}$. The two most important ones are the Erbendorf body (EB), a high-velocity structure that was already known from wide-angle measurements [DEKORP Research Group, 1988; Gebrande et al., 1989], and a new reflector, SE1, steeply dipping northeast in the upper crust. The SE1 is a fault-like continuation of the Franconian Lineament, which at the surface trends roughly NW-SE and separates sediments in the SW from crystalline rocks in the NE. The geometry of these and other structures has become clearer as the migration method used became more advanced, going from poststack migration of an areal set of zero-offset seismograms to prestack migration of all single shots [Körbe et al., 1997; Harjes et al. 1997; Buske, 1999; see also Simon et al., 1996].

[4] So far the ISO-89 3D data set has not been analyzed in order to find seismic-velocity changes at the crustal reflectors below KTB. This goal is of particular interest in the case of the EB and the SE1. Buske [1999] found that 5$10 \%$ of the vibroseis shots produced visible EB and SE1 reflections on shot gathers. This stimulated our study of these responses in single-shot seismograms with only a minor amount of preprocessing and, in particular, without stacking and other techniques which improve the visibility of arrivals, but impair their amplitudes and pulse forms. We obtain data-compatible structural models from comparisons of the observed EB and SE1 reflections with synthetic seismograms.

[5] In the case of the SE1 reflector additional information, supporting the modeling, is available from the borehole geophysics program in the main KTB borehole [ Bram and Draxler, 1995], in particular from the logs of seismic velocities and density. These logs ended at a depth of 8500 $\mathrm{m}$, probably deeper than the SE1 intersection which is supposed to be a zone, a few hundred meters thick, at a depth of about $7000 \mathrm{~m}$ [Harjes et al., 1997; H. Winter, personal communication, 2001]. The logs do not allow a precise localization, but they show strong parameter variations at these depths. This is particularly true for the density $\log$; there is, however, a relation to pronounced borehole breakouts. Smoothing and editing of the logs could only slightly improve the density values, but parts of the $P$ velocity $\log$ showed reduced variations of the order of 515\% [Harjes et al., 1997, Figure 7a, depth range 6500$7100 \mathrm{~m}$ ]. Velocity variations of this size coincide with recent vertical-seismic-profiling measurements in the KTB borehole [Rabbel et al., 2000]. Such velocity changes will later be used in the modeling process of seismograms.

[6] Estimates of reflection coefficients in the upper crystalline crust below the KTB were given by Harjes and coworkers [Harjes and Janik, 1994; Harjes et al., 1997]. From the logs, including the problematic density log, they derived reflection coefficients of up to \pm 0.2 at the SE1. Synthetic seismograms calculated from these coefficients had some similarity with observed SE1 reflections in the INSTRUCT experiment of 1993. However, since the comparison concerned only the pulse form of the reflections, not their absolute amplitudes, the comparison supports only the form of the reflection-coefficient $\log$, not the size of the coefficients. In a second study of reflection coefficients in the KTB volume, Simon [1998] investigated a few pronounced reflections northeast of KTB on the reflection profile KTB 8502. The well-founded method consisted of true amplitude migration of common-offset seismogram sections, a synthetic-seismogram calculation by ray theory and the use of the direct wave as a reference. The method gave very low reflection coefficients with values not exceeding 0.015 . In light of the KTB well $\operatorname{logs}$ such values are not very probable.

[7] This paper is a continuation of such studies with the much larger ISO-89 3D data set, concentrating on the SE1 and the EB. The main information on these structures consists of the amplitude ratios in single-shot seismograms of the SE1 or EB arrival and the first arriving $P_{g}$ phase which serves as a reference signal. True amplitude seismograms without AGC and trace normalization are used. Initially $P_{g}$ modeling is done using a depth-dependent upper crust with low $Q_{p}$ values which explains the amplitude decay and travel times. Then the locations on the EB and SE1 are determined where the identified reflections originate. Finally, seismogram modeling is performed with a hybrid method, combining ray theory and the reflectivity method. Obliquely oriented EB and SE1 reflectors are assumed with a 1-D variation of velocities and density, e.g., first-order discontinuity, laminations and statistical layering. The identified reflections require pronounced contrasts and vertical-incidence reflection coefficients of the order of $0.1-0.15$.

\section{Analysis of the Reference Wave $\boldsymbol{P}_{\boldsymbol{g}}$}

[8] The survey area of the ISO-89 3D seismics is shown in Figure 1. It is an area of $18 \mathrm{~km} \times 18 \mathrm{~km}$ with the location of the KTB drilling site at its center. The Franconian Lineament (FL) separates the area into two parts: the region southwest of the FL is covered by sediments, whereas the region to the northeast is crystalline. The SE1 reflector (steep event 1 ) dips to the northeast at an angle of $\sim 55^{\circ}$ and is a continuation of the FL at depth. Reflection signals from the SE1 can only be recorded in the area northeast of the FL. The present study is restricted to this part of the seismic survey, i.e., to 2500 of 3300 single-shot records (shot traverses 6-21).

[9] The goal of this study is to determine the internal structure and the reflection coefficients of the SE1 and EB by comparing the true amplitude seismic data with synthetic seismograms. The reflected wave field is computed together with the first arriving wave to obtain the correct absolute size of the coefficients. This direct wave is the $P_{g}$ wave which propagates in the upper crystalline crust. An analysis of the $P_{g}$ wave's travel time and amplitude allows the construction of a velocity model which is then used to compute the reflected waves. The waveforms of the $P_{g}$ wave show strong variations and are much more difficult to 


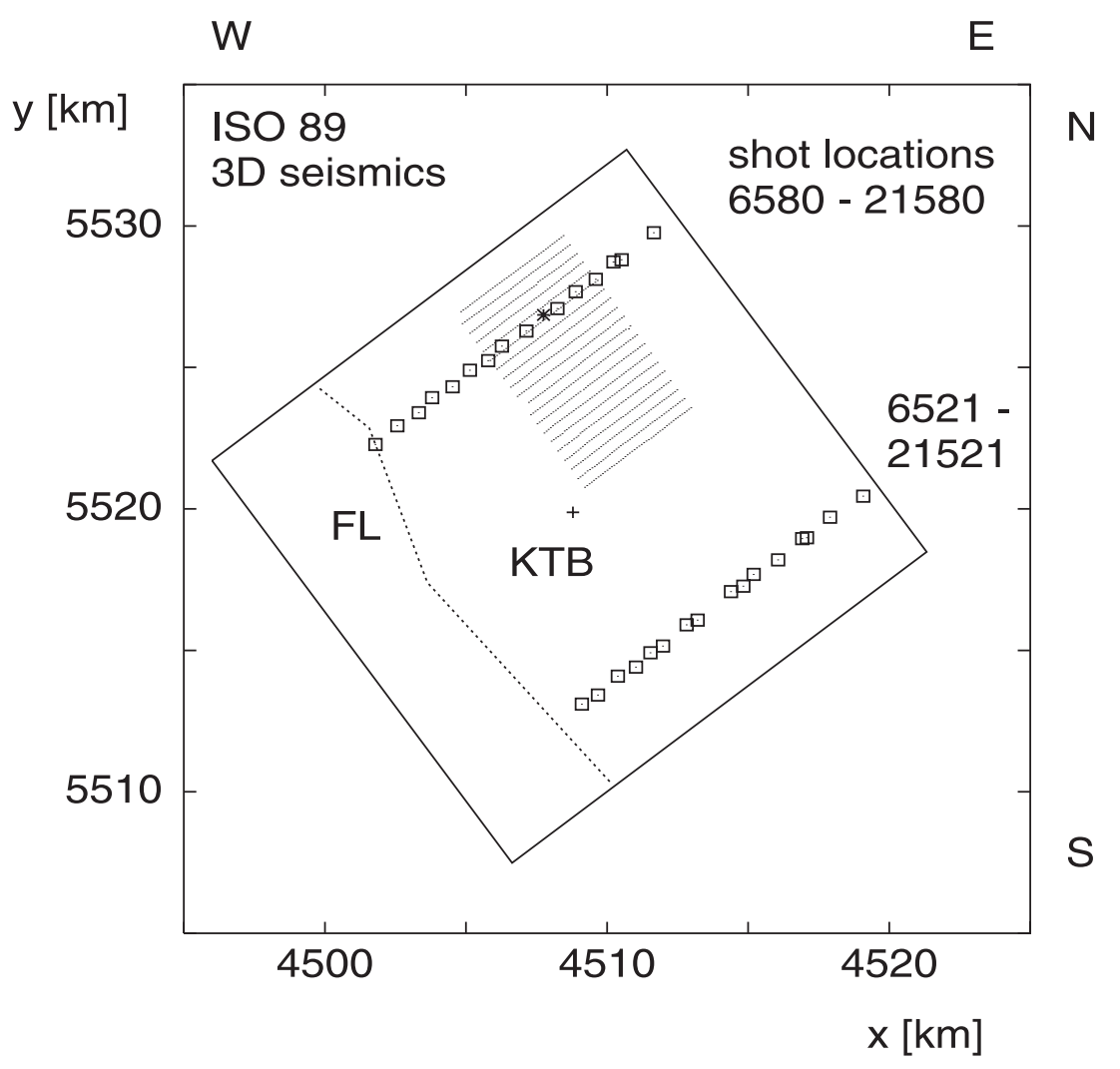

Figure 1. ISO-89 3D seismic survey area with the KTB location $\left(49^{\circ} 48^{\prime} 58.8^{\prime \prime} \mathrm{N}, 12^{\circ} 7^{\prime} 19.2^{\prime \prime} \mathrm{E}\right)$ at its center. $x$ and $y$ are Gauss-Krüger coordinates. 32 shot locations (squares) northeast of the Franconian Lineament (FL) are used for analyzing the $P_{g}$-wave amplitudes. The geophone array of shot location 15580 (star) is shown as an example; it consists of 956 geophones on 20 lines.

interpret (see Figures 4-6 below). These variations can be explained by scattering at local inhomogeneities near the Earth's surface. The $P_{g}$ waveform consists of several cycles, and thus the envelope of the seismic traces is used to measure the amplitude. The envelope is determined from the seismic trace and its Hilbert transform by Fourier transformation [Sheriff and Geldart, 1995]. The $P_{g}$ waveform is sometimes disturbed by correlation noise due to the vibroseis technique which was used as the seismic source (12-48 Hz up-sweep). The correlation noise consists mainly of sinusoidal forerunners [Seriff and Kim, 1970], which make the precise determination of the first-arrival time difficult.

[10] The analysis of the $P_{g}$ amplitudes is performed for the 32 shot locations shown in Figure 1. Shot point 15580 north of the KTB site is shown together with its geophone array. Two shots were performed at this location, each with 10 lines of 48 geophone groups recording the data. The source was located between geophone lines 5 and 6 . The distance between geophone groups was $100 \mathrm{~m}$, and the distance between geophone lines was $400 \mathrm{~m}$. The maximum source-receiver offset was $\sim 6.2 \mathrm{~km}$. The geophone arrays for the other shot points had the same configuration, but were shifted in lateral position. The geophone arrays of the shot locations 6580-21580 extended mainly to the southeast, and the arrays of the locations $6521-21521$ to the northwest. The ray paths of the $P_{g}$ waves of all 32 shot locations covered most of the total survey area northeast of the FL.
[11] The measured $P_{g}$ amplitudes for 20 of the 32 shots are shown in Figure 2 as a function of the source-receiver offset $r$. In Figure 3 the $P_{g}$ amplitudes of shot location 15580 are shown as a function of the geophone number on the 20 parallel receiver lines. A power law is assumed to describe the amplitude decay with offset: $A=c r^{-x}$. The exponent $x$ is determined by a $x^{2}$-fit of a straight line to the data in the form: $\log A=c-x \log r$. The results are shown by the lines in Figures 2 and 3, and the exponents $x$ are given in Table 1. Figures 2 and 3 support the conclusion that the amplitude decay can be described with sufficient accuracy by a power law. The deviations are attributed to lateral velocity and density variations near the Earth's surface. These variations are neglected in the modeling of seismograms.

[12] Part of the irregular $P_{g}$ amplitude variations is probably due to very local conditions and different ground coupling of the geophones. There is some experience with (static) amplitude corrections for such effects on a seismic KTB profile [Oye, 2000]. In this case, further processing of corrected and uncorrected data had similar results. Therefore, no corrections were applied in the present case of 3-D data.

[13] A 1-D velocity-depth model is constructed to explain the $P_{g}$ wave's travel time and amplitude decay. It is known from short-profile refraction measurements that there are high velocities of $4.6-5.8 \mathrm{~km} / \mathrm{s}$ close to the Earth's surface in the region northeast of the FL which is not covered by sediments. These velocities determine the $P_{g}$ wave's travel 

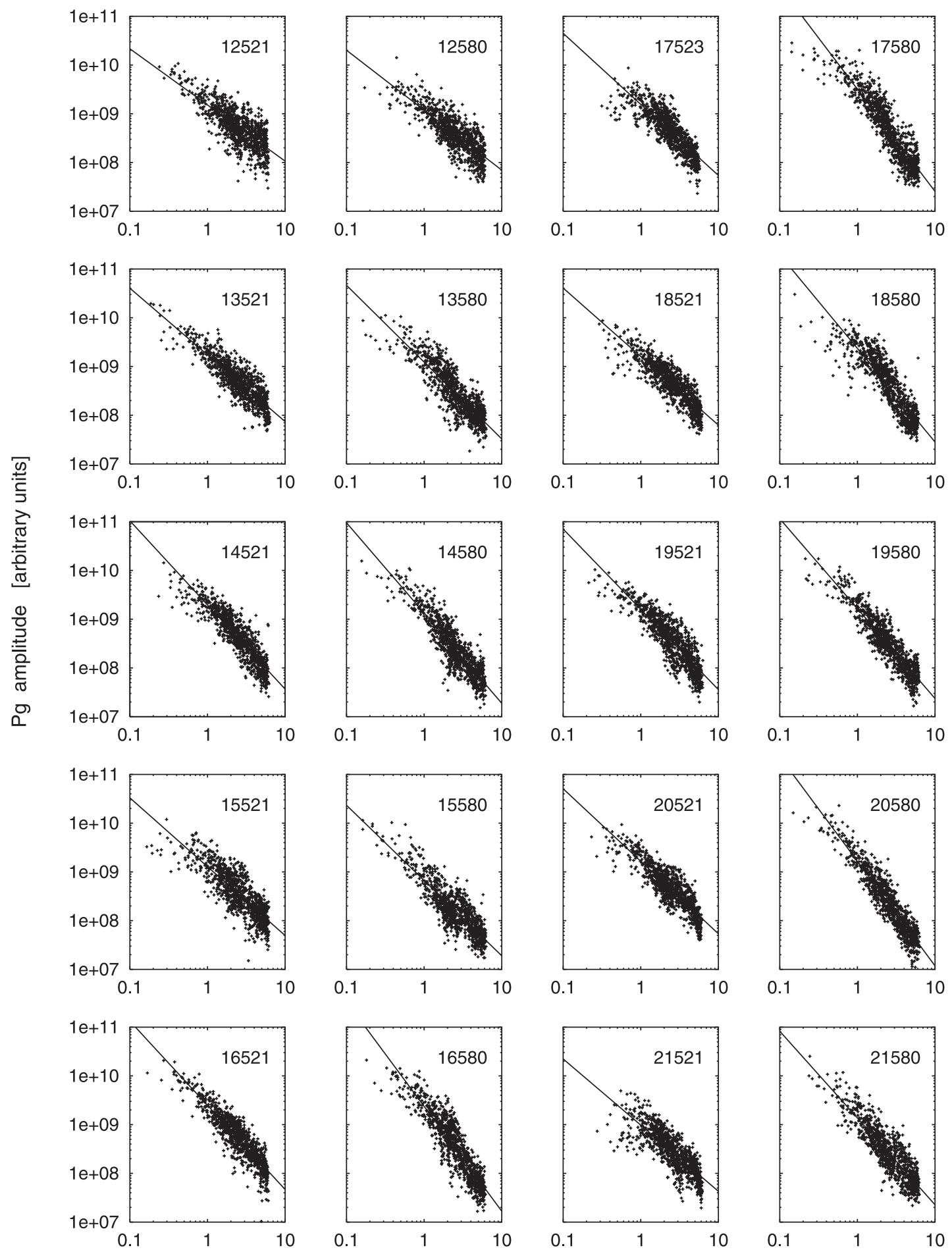

source - receiver offset $\quad r[\mathrm{~km}]$

Figure 2. $P_{g}$ wave amplitudes measured at shot locations $12521-21521$ and $12580-21580$ as a function of lateral distance. Power laws are fitted to the amplitude decay: $\log A=c-x \log r$ with $x$ given in Table 1.

time for the small receiver offsets used in the 3-D survey. The borehole logs show that $v_{p}=6 \mathrm{~km} / \mathrm{s}$ is reached at $\sim 1 \mathrm{~km}$ depth and that $v_{p}=6.3 \mathrm{~km} / \mathrm{s}$ at $\sim 3 \mathrm{~km}$ depth [Bram and Draxler, 1995]. The last mentioned value is the average $P$ velocity for greater depths. The information from the bore- hole $\operatorname{logs}$ is used to construct two layers with linear velocity-depth functions. The velocity at the Earth's surface and the velocity gradient in the first layer are chosen so that the best fit for all travel times of a single shot is obtained. The shear wave velocity $v_{s}$ is set to $v_{p} / \sqrt{3}$, a value which is 

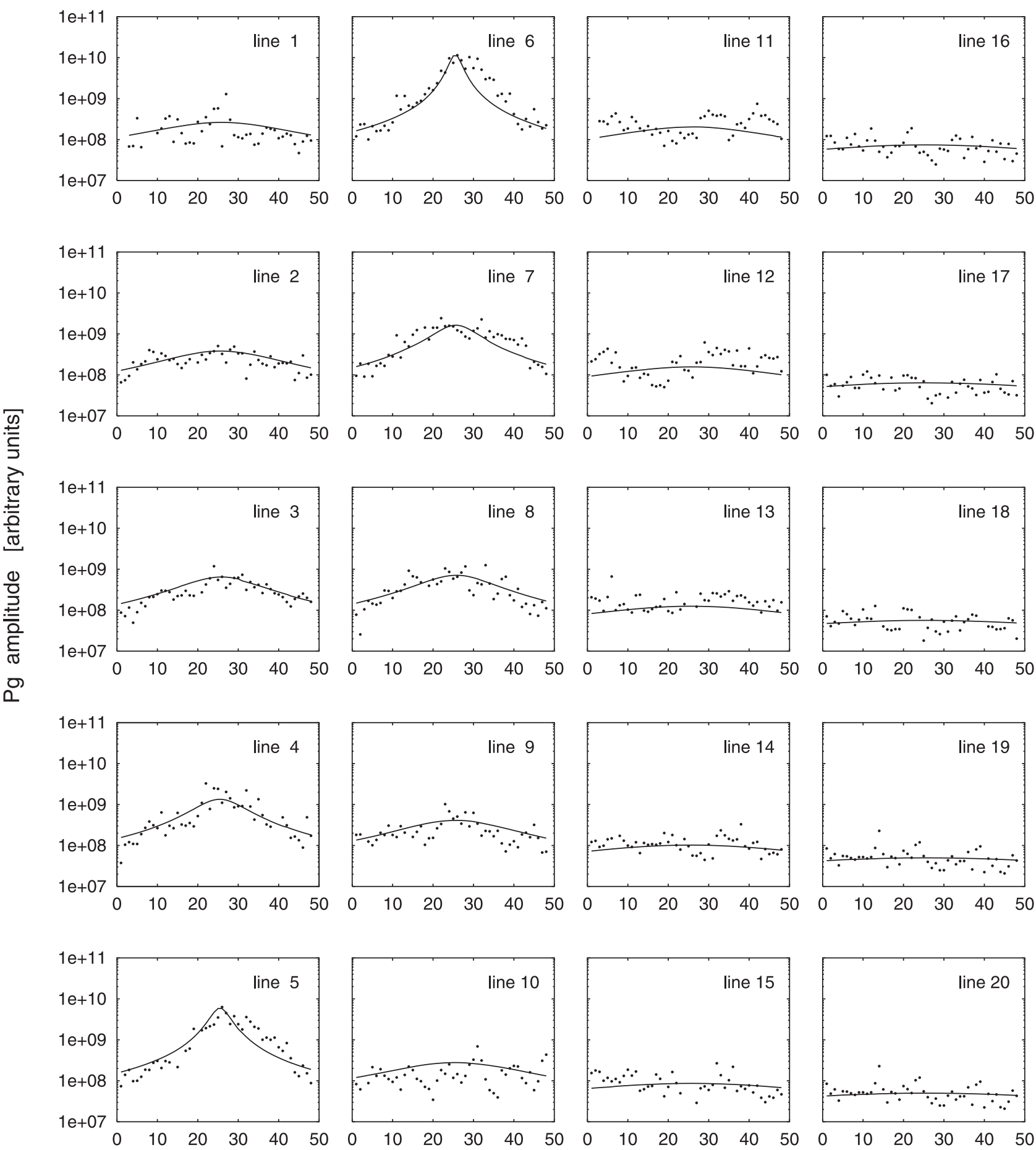

\section{geophone number}

Figure 3. $P_{g}$ wave amplitudes, measured at 956 geophone positions of shot location 15580. The function $\log A=c-x \log r$ is fitted to the data on each geophone line; $A$ is the $P_{g}$ amplitude and $r$ is the shot-receiver offset. The line length is $4.7 \mathrm{~km}$.

confirmed by the well logs and by the travel times of the $S_{g}$ wave which occasionally can be identified in the single-shot sections. The density is determined by the Nafe-Drake relation for crustal rocks: $\rho=1.8+0.15 v_{p}$ [Grant and West, 1965, Figure 7-7].

[14] Ray theory shows that the $P_{g}$ wave travels in the gradient layer with a maximum depth of a few hundred meters (2-5 wavelengths). The amplitude decay in a fullspace with a linear velocity-depth function is given for small offsets $r$ by $1 / r$ [Officer, 1958]. If a stress-free surface is introduced, the wave propagation becomes much more complicated. The direct wave then consists of all interfering waves which are multiply reflected at the surface. This wave is known as an interference head wave [Červený and 
Table 1. $P_{g}$ Wave Amplitude Decay $\sim 1 / r^{x \text { a }}$

\begin{tabular}{cccc}
\hline Shot Location & $x$ & Shot Location & $x$ \\
\hline 6521 & 1.8 & 6580 & 1.8 \\
7521 & 1.3 & 7580 & 1.6 \\
8521 & 1.5 & 8580 & 1.4 \\
9521 & 1.1 & 9580 & 1.6 \\
10521 & 1.0 & 10580 & 1.4 \\
11521 & 1.1 & 11580 & 1.4 \\
12521 & 1.2 & 12580 & 1.2 \\
13521 & 1.4 & 13580 & 1.6 \\
14521 & 1.7 & 14580 & 1.9 \\
15521 & 1.4 & 15580 & 1.5 \\
16521 & 1.7 & 16580 & 2.1 \\
17523 & 1.5 & 17580 & 2.1 \\
18521 & 1.4 & 18580 & 1.9 \\
19521 & 1.6 & 19580 & 1.8 \\
20521 & 1.5 & 20580 & 2.1 \\
21521 & 1.4 & 21580 & 1.8 \\
\hline
\end{tabular}

${ }^{\mathrm{a}} r$ is the source-receiver offset.

Ravindra, 1971]. Because analytical results are difficult to obtain, the reflectivity method is used to compute synthetic seismograms for a half-space with a linear velocity-depth function. The velocity gradient is approximated by using a sequence of homogeneous layers with layer thickness smaller than a quarter of the wavelength. The source is described by a vertical point force which acts on the free surface. A frequency-independent $Q_{p}$ factor is chosen in such a way that the measured amplitude decay with offset is reproduced; $Q_{s}$ is set to $4 / 9 Q_{p}$, a standard relation for media with $v_{s}=v_{p} / \sqrt{3}$ and intrinsic attenuation only in shear, not in compression.

[15] The velocity-depth functions for a number of selected shots, whose reflection signals from the SE1 and the EB are studied quantitatively below, are shown in Table 2. These models explain the observed $P_{g}$ travel times within $0.1 \mathrm{~s}$. Compared with the observed seismogram sections in Figures 4-6 below, this is a sufficient approximation. The models explain the $P_{g}$ amplitude decay; synthetic $P_{g}$ waveforms are close to the vertical-force source time function, a Ricker wavelet with dominant frequency $30 \mathrm{~Hz}$. The $Q_{p}$ values are quite low $(<100)$, indicating strong damping in the first few hundred meters depth. Such low $Q$ values have been previously reported for even greater depths at the KTB boreholes. For a number of shots predominantly in the northeastern part of the survey area, the $P_{g}$ amplitudes decay $\sim r^{-2.4}$. In case of a half-space with constant velocity a low quality factor of $Q_{p}=40$ would be needed to reproduce this rapid amplitude decay. The introduction of a velocity gradient reduces the amplitude decay and has to be compensated for by even smaller $Q_{p}$ values. The problem is further discussed in the following sections and in Appendix A.

\section{Reflections From the SE1 Reflector and From the Erbendorf Body}

[16] The 1800 single-shot sections, recorded northeast of the FL, were examined for crustal reflection signals, i.e., $\sim 10^{6}$ seismograms (shot traverses 11-21). Clearly visible signals from the SE1 reflector were found in 10,000 traces of 80 shots and from the EB reflector in 6000 traces of 70 shots.

[17] Three single-shot records are shown in Figures 4, 5, and 6 with the first $5 \mathrm{~s}$ of $12 \mathrm{~s}$ recording time; static corrections are applied. The frequency content of the data corresponds to the $12-48 \mathrm{~Hz}$ frequency band of the vibroseis source. Every second trace is plotted in the first $1.5 \mathrm{~s}$ to reveal the waveform of the $P_{g}$ signals, and a scaling factor $\sim r^{x}$ is applied to compensate for the $P_{g}$ wave's amplitude decay with offset. In the time interval between 1.5 and $5 \mathrm{~s}$ the seismograms are shown with true amplitudes. The receiver lines $1-4$ of shot 18615 are shown in Figure 4 . The SE1 reflections can clearly be seen in the time interval between 2.5 and $3.1 \mathrm{~s}$. Previous migration results have shown that the SE1 dips steeply to the northeast at an angle of $\sim 55^{\circ}$ [Körbe et al., 1997; Buske, 1999]. The geophone lines are orthogonal to its strike, and, therefore, the arrival time of the SE1 reflection increases on each geophone line from the left to the right. Figure 5 displays lines 5-8 of shot 17642 , with the EB reflection arriving in the time interval from 4.1 to $4.4 \mathrm{~s}$. The travel time decreases along each geophone line and from one line to the next, which indicates that this part of the EB is a dipping structure. In Figure 6 the geophone lines 1-4 of shot 18735 are shown. It is one of the few cases where both SE1 and EB reflections are visible.

[18] A number of reflections with travel times between 3.2 and $4.8 \mathrm{~s}$ can be identified in single-shot sections of the ISO89 3D data set. They were previously identified in stacked data volumes and named by the letters B, G and R [Wiederhold, 1992]. The $\mathrm{B}$ and $\mathrm{G}$ reflections were attributed to the $\mathrm{EB}$, but whether the $\mathrm{R}$ reflections $\mathrm{R} 1$ and $\mathrm{R} 10$ also belong to the EB remained undetermined. It is known from wide-angle measurements, that the EB has a considerable lateral extension [DEKORP Research Group, 1988; Gebrande et al., 1989]. Therefore, in this study we take the view that all signals with travel times between 3.2 and $4.8 \mathrm{~s}$ are reflections from the EB. Most of the 6000 reflections from the EB are from the reflector R1. We determined an image of this reflector using Kirchhoff migration with a constant velocity of $6.3 \mathrm{~km} / \mathrm{s}$ [Schneider, 1978]. The absolute values of the migrated amplitudes of the single shots were stacked

Table 2. Selected Single-Shot Sections With Crustal Reflections From SE1 and $\mathrm{EB}^{\mathrm{a}}$

\begin{tabular}{lcccc}
\hline Reflector & Shot/Swath & $x$ & $v_{p}(z), \mathrm{km} / \mathrm{s}$ & $Q_{p}$ \\
\hline SE1 & $18615 / 1$ & 1.4 & $5.3+0.7 z$ & 50 \\
SE1 & $15620 / 1$ & 1.4 & $5.5+0.5 z$ & 70 \\
SE1 & $17622 / 1$ & 1.0 & $5.5+0.5 z$ & 200 \\
SE1 & $18734 / 2$ & 1.7 & $5.1+0.9 z$ & 30 \\
SE1 & $18735 / 2$ & 1.6 & $5.1+0.9 z$ & 35 \\
SE1 & $17799 / 4$ & 2.4 & $5.1+0.9 z$ & 15 \\
SE1 & $19800 / 4$ & 2.5 & $5.3+0.7 z$ & 15 \\
EB (R1) & $15638 / 1$ & 1.3 & $5.3+0.7 z$ & 60 \\
EB (R1) & $15738 / 2$ & 1.5 & $5.2+0.8 z$ & 40 \\
EB (R1) & $15743 / 2$ & 1.3 & $5.2+0.8 z$ & 50 \\
EB (R1) & $16753 / 2$ & 1.7 & $5.3+0.7 z$ & 35 \\
EB (R1) & $17642 / 3$ & 1.8 & $5.1+0.9 z$ & 25 \\
EB (G) & $21610 / 1$ & 1.8 & $5.1+0.9 z$ & 25 \\
EB (B) & $14631 / 1$ & 1.6 & $5.4+0.6 z$ & 45 \\
EB (B) & $17741 / 2$ & 1.5 & $5.3+0.7 z$ & 45 \\
EB (B) & $14645 / 3$ & 2.5 & $5.1+0.9 z$ & 10 \\
EB (R10) & $19796 / 4$ & 2.1 & $5.3+0.7 z$ & 20 \\
EB (R10) & $18799 / 4$ & 2.4 & $5.1+0.9 z$ & 15 \\
\hline
\end{tabular}

${ }^{\mathrm{a}}$ The 1-D velocity-depth function and the $Q_{p}$ factors for the depth interval $z<1 \mathrm{~km}$ explain the observed $P_{g}$ wave travel time and amplitude decay with offset $\sim 1 / r^{x}$. The labels R1, R10, B, and G coincide with those of Wiederhold [1992]; see also Figure 8. 


\section{ISO 89 - 3D reflection seismics: source location 18615}

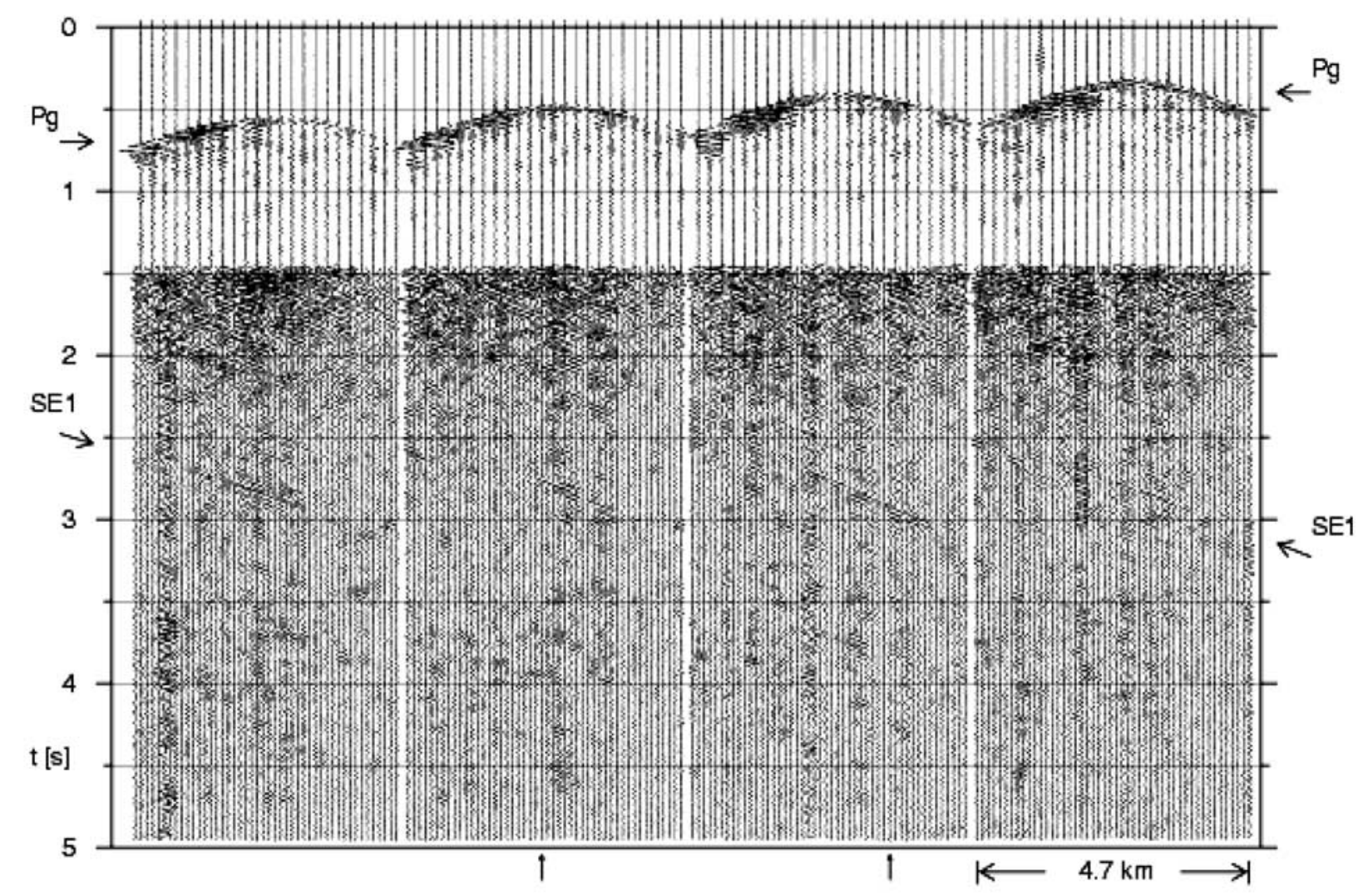

Figure 4. ISO-89 3D data example: Seismograms of shot 18615 (receiver lines 1-4). The signals of the dipping SE1 reflector arrive in the time interval between 2.5 and $3.1 \mathrm{~s}$. Between 1.5 and $5 \mathrm{~s}$, true amplitudes are shown. In the first $1.5 \mathrm{~s}$, every second trace is plotted and an offset-dependent scaling factor $\sim r^{1.4}$ is applied to reveal the waveform of the $P_{g}$ signals. Traces 70 and 129 are marked with an arrow (compare to Figure 10).

[Buske, 1999]. The result is shown in Figure 7. The EB (R1) appears as a dipping structure of $\sim 5 \mathrm{~km}$ lateral extension.

[19] Geometrical ray theory is used to obtain a map of the reflection points. The $\mathrm{G}, \mathrm{B}$, and $\mathrm{R} 10$ reflections with travel times of $3.2-3.3 \mathrm{~s}, 3.5-3.6 \mathrm{~s}$, and $4.7-4.8 \mathrm{~s}$ are represented by horizontal interfaces at 10,11 , and $15 \mathrm{~km}$ depth, respectively. The $\mathrm{R} 1$ reflector is modeled by a plane, dipping with $30^{\circ}$ to the north and with $10^{\circ}$ to the west (and including the point $(4514,5516,11) \mathrm{km})$; the reflection points are in the depth range between 8.5 and $11.5 \mathrm{~km}$. The SE1 has a strike angle of $320^{\circ}$ and a dip angle between $45^{\circ}$ and $60^{\circ}$ (including the point $(4510,5511,0) \mathrm{km}$ ); the dip angle is chosen in such a way that the measured SE1 travel times are reproduced in the best way. The reflection points for the SE1 and the EB are shown in Figure 8. The SE1 reflection points are concentrated in three regions: at $6 \mathrm{~km}$ southeast of the KTB in the depth interval $3.8-5.4 \mathrm{~km}$ (including the reflection points of shots 18615,15620 , and 17622 in Table 2), at $3.5 \mathrm{~km}$ south in $4.3-5.2 \mathrm{~km}$ depth (shots 18734 and 18735) and at $8 \mathrm{~km}$ northwest in 5.1-6.4 km depth (shots 17799 and 19800). The angles of incidence are smaller than $15^{\circ}$ for both reflectors SE1 and EB.
[20] The thickness of the EB, or more properly, of its reflecting top part, is constrained by the length of the reflection signal in the data. It does not exceed the signal length of the $P_{g}$ wave. Reflection signals from deeper parts or even from the bottom of the EB, separated in time from the first signal, cannot be found in the data. Taking an EB reflection length of about $0.1 \mathrm{~s}$ as the two-way time of the reflecting part of the EB, an upper limit for the thickness of this zone of $350 \mathrm{~m}$ is found, using a velocity of $7 \mathrm{~km} / \mathrm{s}$. Thus the thickness of the reflecting part of the EB is much smaller than its lateral extension. The thickness of the SE1 can be estimated in a similar way and with similar results from the duration of the SE1 reflection signal.

\section{Comparison of Single-Shot Sections and Synthetic Seismograms}

[21] For the computation of synthetic SE1 and EB reflections a combination of the ray method and the reflectivity method is used. This hybrid method allows the investigation of thin dipping reflectors with a complicated internal 1-D structure. The reflectors can be embedded in an inhomoge- 


\section{ISO 89 - 3D reflection seismics: source location 17642}

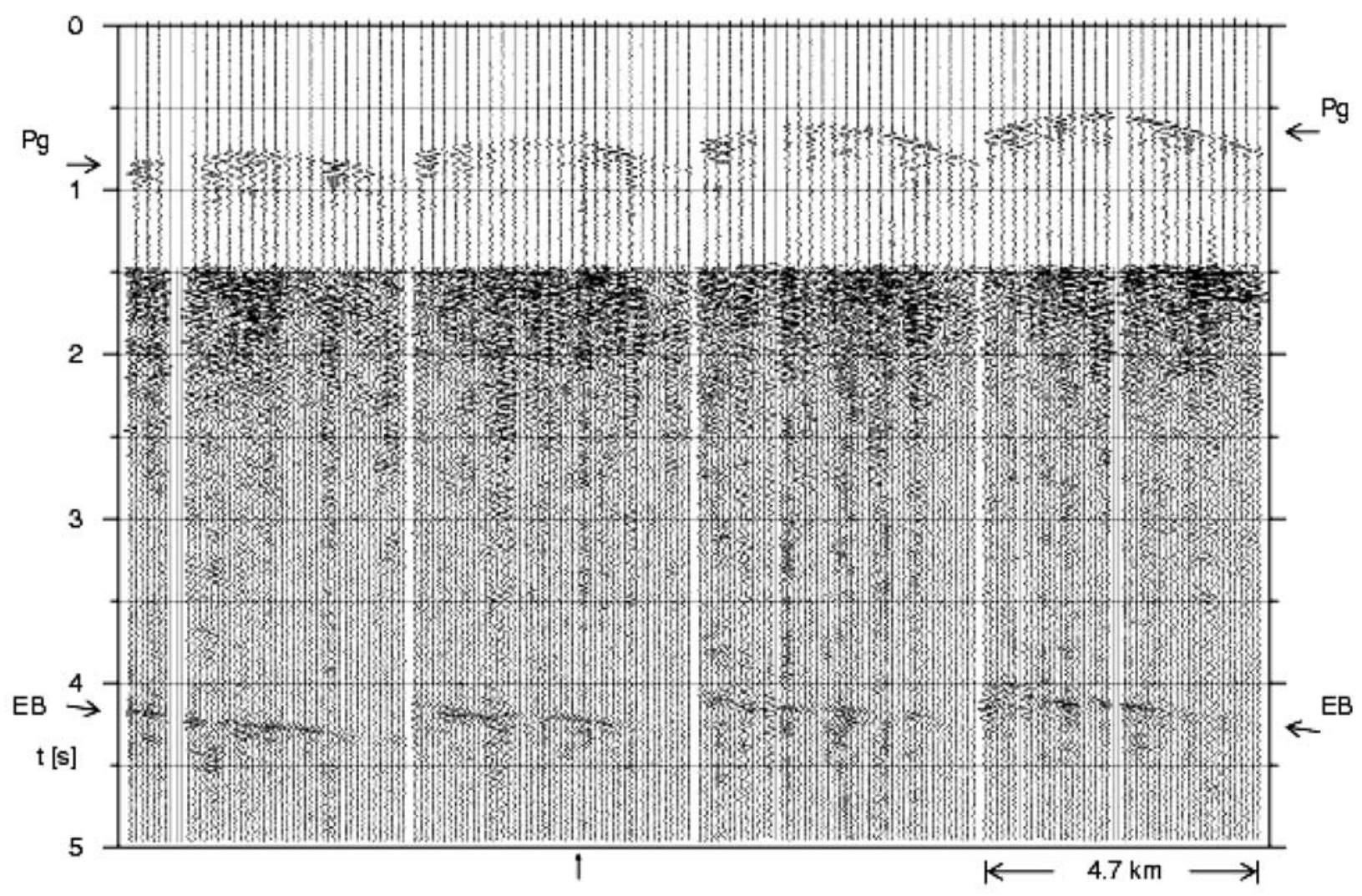

Figure 5. ISO-89 3D data example: Seismograms of shot 17642 (receiver lines 5-8). The EB reflections arrive in the time interval between 4 and $4.3 \mathrm{~s}$. Between 1.5 and $5 \mathrm{~s}$, true amplitudes are shown. In the first $1.5 \mathrm{~s}$, every second trace is plotted and an offset dependent scaling factor $\sim r^{1.8}$ is applied to reveal the waveform of the $P_{g}$ signals. Trace 267 is marked with an arrow (compare to Figure 10).

neous medium with a 3-D velocity distribution. At the reflection point, the frequency-dependent reflection coefficient for a stack of layers is computed. The radiation pattern for a vertical-force point source at the free surface is included in the implementation, as well as the free-surface transfer function at the receivers. The six ordinary differential equations for a seismic ray in a 3-D inhomogeneous medium are solved together with the twelve additional differential

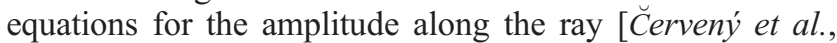
1977]. The ray which reaches the receiver position is calculated by varying the take-off angles at the source position (the boundary value problem is solved through varying the initial values). The system of ordinary differential equations is integrated using the program lsodar of the odepack library [Petzold, 1983]. This program automatically chooses the step size, controls the integration error and contains a root searching option which is useful in finding the point of intersection of a ray with the reflector plane.

[22] Synthetic seismograms for comparison with the ISO$893 \mathrm{D}$ data were computed using a simple velocity model (section 2): the velocity laws and $Q_{p}$ factors of Table 2 are used for the depth range $0<z<1 \mathrm{~km}$. They give the correct amplitude decay of the $P_{g}$ wave as discussed in section 2 . The velocity increases linearly between 1 and $3 \mathrm{~km}$ depth from 6 to $6.3 \mathrm{~km} / \mathrm{s}$; for $z>3 \mathrm{~km}$ the constant velocity $6.3 \mathrm{~km} / \mathrm{s}$ is used. The SE1 and the EB are represented by dipping plane interfaces or stacks of layers (see section 3). Seismograms are calculated for the true source and receiver coordinates. The source pulse is again a $30 \mathrm{~Hz}$ Ricker wavelet.

[23] The quality factor $Q_{p}$ of the crystalline crust for $z>1 \mathrm{~km}$ was set to the values: infinite, 500 and 250. Low attenuation, as represented by these values, is found in crustal studies of earthquake and explosion seismology [e.g., Kvamme and Havskov, 1989; Scheirer and Hobbs, 1990; Fletcher et al., 1990; Aster and Shearer, 1991; Havskov and Medhus, 1991; Grad and Luosto, 1994; Benz et al., 1997; Adams and Abercrombie, 1998]. These studies contrast with the results of vertical-seismic profiling (VSP) investigations at KTB. Very low $Q_{p}$ values from 20 to 50 were reported for the main borehole by $\mathrm{Li}$ [1995] and Pujol et al. [1998]. Appendix A provides a reinterpretation of their VSP seismogram section and shows that these data give evidence both for low and for very high $Q_{p}$ and that, therefore, no representative $Q_{p}$ values can be derived for a larger rock volume. Moreover, $Q_{p}$ values much lower than 500 would entail reflection coefficients for the SE1 and the EB which are unrealistically high, even larger than 1.

[24] The amplitude ratios $\mathrm{SE} 1 / P_{g}$ and $\mathrm{EB} / P_{g}$ in the data are determined for the shots given in Table 2; amplitudes are envelope values. The results are shown in Figure 9. The 


\section{ISO 89 - 3D reflection seismics: source location 18735}

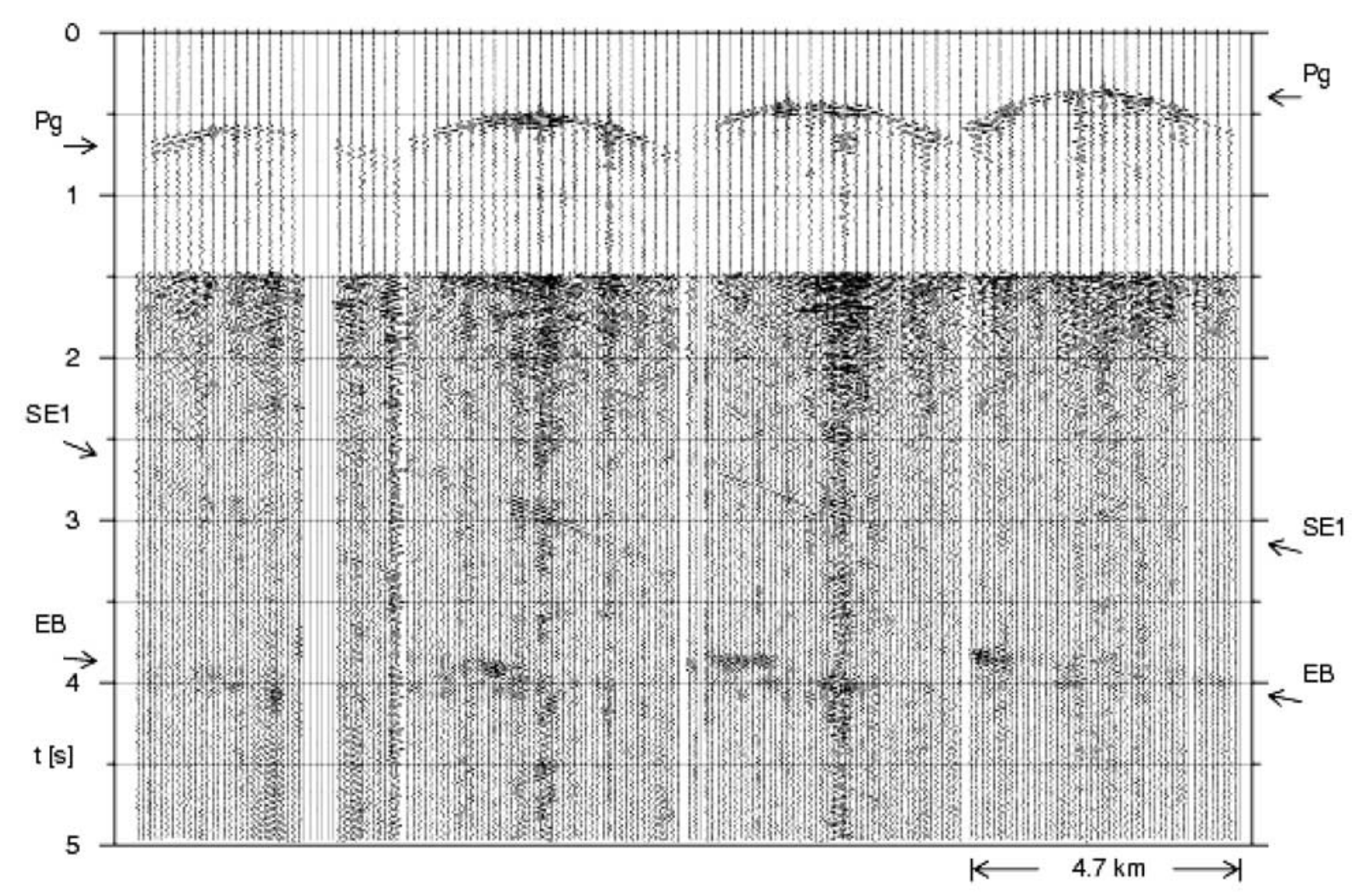

Figure 6. ISO-89 3D data example: Seismograms of shot 18735 (receiver lines 1-4). The SE1 reflections arrive in the time interval between 2.7 and $3.3 \mathrm{~s}$, and the EB reflections between 3.8 and $4.0 \mathrm{~s}$. Between 1.5 and $5 \mathrm{~s}$, true amplitudes are shown. In the first $1.5 \mathrm{~s}$, every second trace is plotted and an offset dependent scaling factor $\sim r^{1.6}$ is applied to reveal the waveform of the $P_{g}$ signals.

synthetic, straight-line amplitude ratios correspond to reflectors which are first-order discontinuities with different reflector velocities (the velocity of the overburden is $6.3 \mathrm{~km} / \mathrm{s}$ ). The velocity decreases in the SE1 models, based on the assumption that the SE1 is a fault zone; the velocity increases in the EB reflector models, according to our knowledge from wide-angle measurements. In both cases, the polarity of the reflections in the data could not be determined because of background noise. The positive slope of the lines in Figure 9 is due to the decay of the $P_{g}$ amplitudes. The central line gives the best fit to the observed amplitude ratios.

[25] Several models which explain the measured amplitude ratios in about the same way are given in Table 3. The size of the velocity jumps depend on the assumptions about the damping at depths between $z=1 \mathrm{~km}$ and the reflectors. We prefer the value $Q_{p}=500$. A value of $Q_{p}=250$ leads to velocities higher than $8.0 \mathrm{~km} / \mathrm{s}$ for the $\mathrm{EB}$, which is petrologically less plausible. The first-order discontinuities require high-velocity contrasts, and the $\lambda / 4$ layers require smaller contrasts due to constructive interference produced by the layer. The reflection coefficients given are for the first-order discontinuity models; they include a density contribution. Typical magnitudes are $0.1-0.2$, depending on $Q_{p}$; for the $\lambda / 4$ layers the values would be somewhat lower.
[26] A direct comparison of observed seismograms, taken partly from Figures 4 and 5, and synthetic seismograms is given in Figure 10. The models used are: a first order discontinuity, a $\lambda / 4$ layer, three layers and two models which are quasi-statistical and consist of 15 and 30 layers with thicknesses of 5,10 or $20 \mathrm{~m}$. The autocorrelation function of the vibroseis sweep $(12-48 \mathrm{~Hz})$ is used as the signal. The models produce time signals of $0.1-0.15 \mathrm{~s}$ length and with similar amplitudes. The synthetic traces are calculated for the comparison with trace 70 of shot 18615 and trace 119 of shot 17642 . A travel time error of $0.1 \mathrm{~s}$ is acceptable. Detailed reproduction of observed pulse forms is not possible because of scattering and noise contributions in all data traces, but the pulse durations compare favorably.

\section{Discussion and Conclusions}

[27] The pulse durations of the SE1 and EB reflections are no longer than the $P_{g}$ duration, as the seismogram sections in Figures 4-6 show. Accordingly, the reflectors could even be first-order discontinuities. For the SE1 this is improbable, because the $P$ velocity log of the KTB main borehole does not show a velocity step of the required size of $1 \mathrm{~km} / \mathrm{s}$ or more (Table $3, Q_{p}=500$ ). For the largest EB 

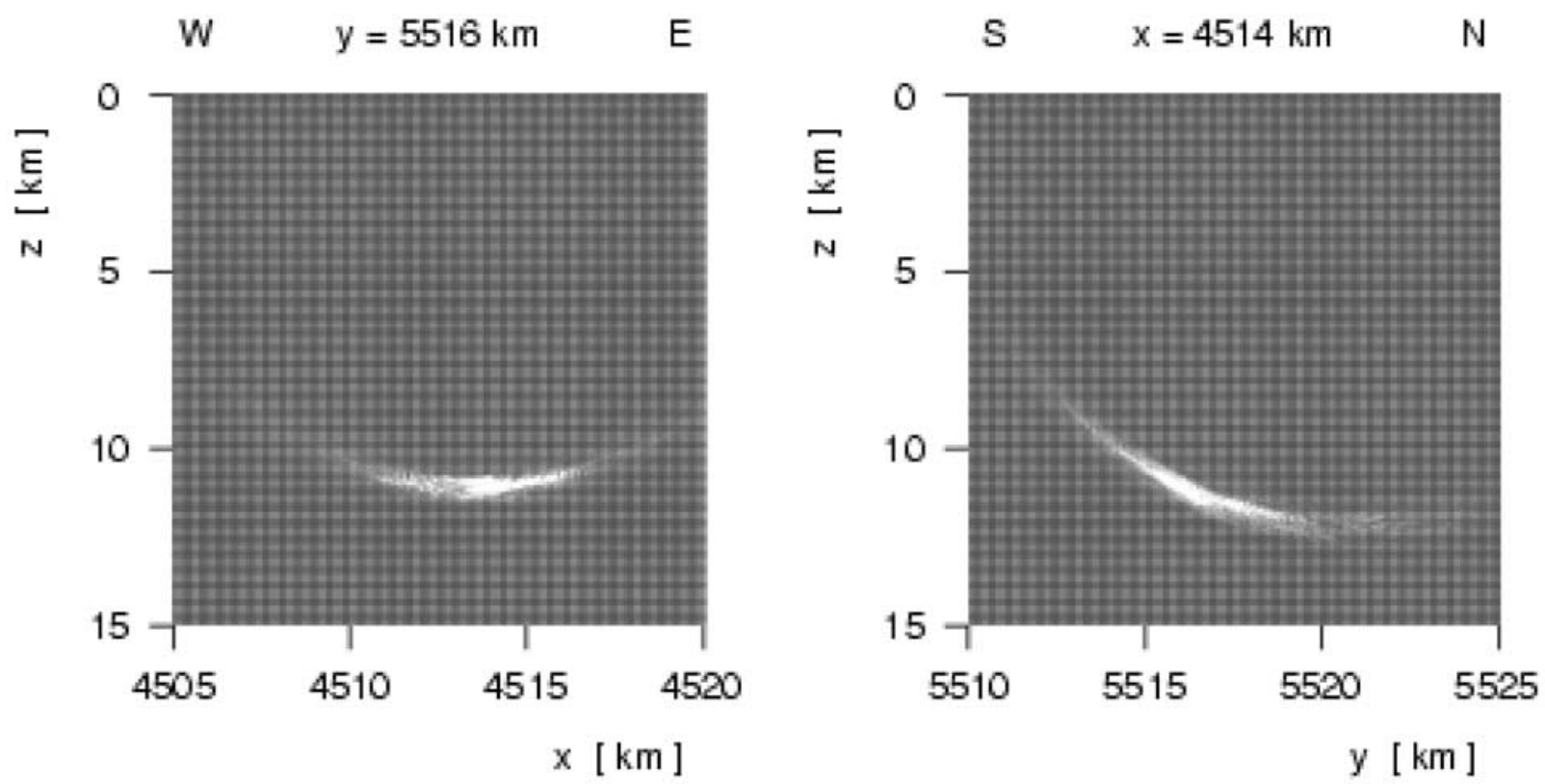

Figure 7. Kirchhoff-migration: Vertical W-E and S-N slices through the EB. The slices pass through the center of the main cluster (R1) of EB reflection points in Figure 8.

reflection zone R1 (Figure 8), a step of $1.5 \mathrm{~km} / \mathrm{s}$ and higher would be required (Table $3, Q_{p}=500$ ), which is difficult to explain petrologically. For the SE1 and EB part R1, laminated structures with reduced velocity contrasts are plausible alternative models (Figure 10, Table 3). Their total thickness can hardly exceed $300 \mathrm{~m}$, otherwise the duration of the reflections would be too long. For the SE1 a thickness range from 50 to $300 \mathrm{~m}$ is permitted. If the EB were only $300 \mathrm{~m}$ thick, its refracted wave (with velocities higher than
$7 \mathrm{~km} / \mathrm{s}$ ) would not have been observed in wide-angle measurements for tens of kilometers [DEKORP Research Group, 1988; Gebrande et al., 1989]. Consequently, the steep-angle ISO-89 3D measurements have only detected the top of the EB. Times greater than $5 \mathrm{~s}$ were also investigated in this data set, but no clear arrivals, including the Moho reflection, could be determined. The interior of the EB appears to have smooth velocity variations. A smooth decrease from an average velocity of $7.5 \mathrm{~km} / \mathrm{s}$ at
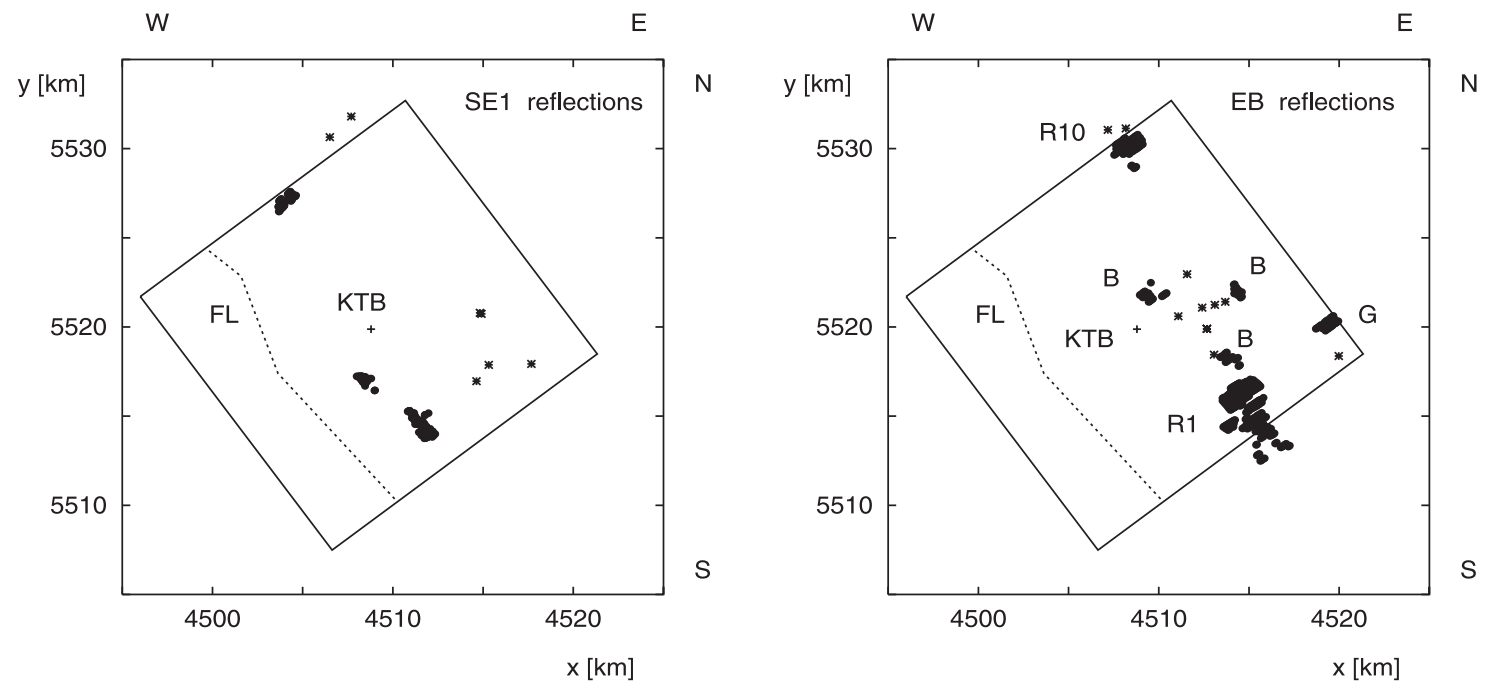

Figure 8. Map of reflection points for the SE1 and the EB reflector, determined by ray tracing and projected vertically to the earth's surface. The stars denote the source locations used (see Table 2 or 3 ). The Gauss-Krüger coordinates of the shots 18615,17642 and 18735 are given by (4517.674 km, $5517.925 \mathrm{~km}),(4513.109 \mathrm{~km}, 5521.243 \mathrm{~km})$ and $(4514.824 \mathrm{~km}, 5520.789 \mathrm{~km})$, respectively (compare to Figures 4-6). The labels B, G, R1, and R10 coincide with the denotations of Wiederhold [1992]. 

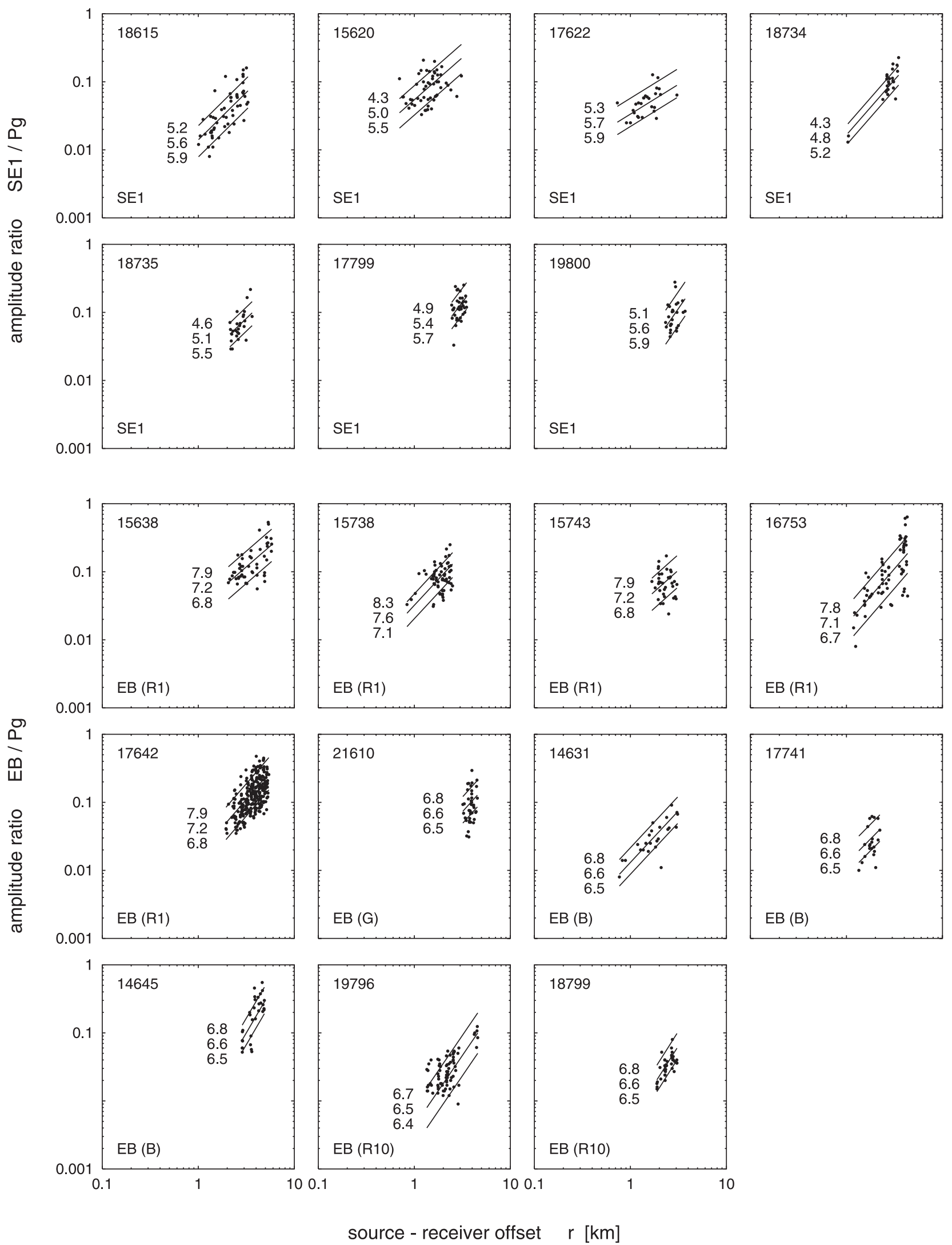

Figure 9. Amplitude ratios of the SE1 and the EB reflection with the direct $P_{g}$ wave as a function of the source-receiver offset. Shot numbers as in Tables 2 and 3. The data (dots) are compared to results from synthetic seismograms (lines). The background velocity is $6.3 \mathrm{~km} / \mathrm{s}$. The three model curves are calculated for different reflector velocities, assuming a first-order discontinuity and a quality factor $Q_{p}=\infty$ for $z>1 \mathrm{~km}$ (compare Table 3 for other models). 
Table 3. Reflector Velocities $v_{p}$ and Reflection Coefficients $R_{p p}$ of the SE1 and the EB ${ }^{\mathrm{a}}$

\begin{tabular}{|c|c|c|c|c|c|c|c|}
\hline \multirow[b]{3}{*}{ Reflector } & \multirow[b]{3}{*}{ Shot/Swath } & \multicolumn{4}{|c|}{$v_{p}, \mathrm{~km} / \mathrm{s}$} & \multirow{2}{*}{\multicolumn{2}{|c|}{$\begin{array}{c}R_{p p} \\
\text { First-Order Discontinuity }\end{array}$}} \\
\hline & & \multicolumn{2}{|c|}{ First-Order Discontinuity } & \multicolumn{2}{|c|}{$\lambda / 4$ Layer } & & \\
\hline & & $Q_{p}=\infty$ & $Q_{p}=500$ & $Q_{p}=500$ & $Q_{p}=250$ & $Q_{p}=\infty$ & $Q_{p}=500$ \\
\hline SE1 & $18615 / 1$ & 5.6 & 5.3 & 5.7 & 5.4 & -0.08 & -0.11 \\
\hline SE1 & $15620 / 1$ & 5.0 & 4.6 & 5.2 & 4.9 & -0.15 & -0.20 \\
\hline SE1 & $17622 / 1$ & 5.7 & 5.4 & 5.7 & 5.6 & -0.06 & -0.10 \\
\hline SE1 & $18734 / 2$ & 4.8 & 4.3 & 4.9 & 4.5 & -0.17 & -0.23 \\
\hline SE1 & $18735 / 2$ & 5.1 & 4.7 & 5.2 & 4.8 & -0.13 & -0.18 \\
\hline SE1 & $17799 / 4$ & 5.4 & 5.2 & 5.5 & 5.2 & -0.10 & -0.12 \\
\hline SE1 & $19800 / 4$ & 5.6 & 5.4 & 5.6 & 5.4 & -0.08 & -0.10 \\
\hline EB (R1) & $15638 / 1$ & 7.2 & 7.9 & 7.3 & $(8.1)$ & 0.09 & 0.15 \\
\hline EB (R1) & $15738 / 2$ & 7.6 & $(8.8)$ & 7.8 & $(9.0)$ & 0.13 & 0.22 \\
\hline EB (R1) & $15743 / 2$ & 7.2 & $(8.0)$ & 7.3 & $(8.2)$ & 0.09 & 0.16 \\
\hline EB (R1) & $16753 / 2$ & 7.1 & 7.8 & 7.3 & $(8.0)$ & 0.08 & 0.14 \\
\hline EB (R1) & $17642 / 3$ & 7.2 & 7.9 & 7.4 & (8.2) & 0.09 & 0.15 \\
\hline EB (G) & $21610 / 1$ & 6.6 & 6.8 & 6.6 & 6.8 & 0.03 & 0.05 \\
\hline EB (B) & $14631 / 1$ & 6.6 & 6.8 & 6.6 & 6.9 & 0.03 & 0.05 \\
\hline EB (B) & $17741 / 2$ & 6.6 & 6.8 & 6.6 & 6.8 & 0.03 & 0.05 \\
\hline EB (B) & $14645 / 3$ & 6.6 & 6.8 & 6.6 & 6.8 & 0.03 & 0.05 \\
\hline EB (R10) & $19796 / 4$ & 6.5 & 6.7 & 6.6 & 6.8 & 0.02 & 0.04 \\
\hline $\mathrm{EB}(\mathrm{R} 10)$ & $18799 / 4$ & 6.6 & 6.8 & 6.6 & 6.9 & 0.03 & 0.05 \\
\hline
\end{tabular}

${ }^{\text {a }}$ The $P$ wave velocity above the reflectors is $6.3 \mathrm{~km} / \mathrm{s}$. Several $Q$ models in the depth range $z>1 \mathrm{~km}$ are considered. The thickness of the $\lambda / 4$ layer is related to the frequency $30 \mathrm{~Hz}$. Velocities which are petrologically implausible are given in parentheses.

SE1 reflector models

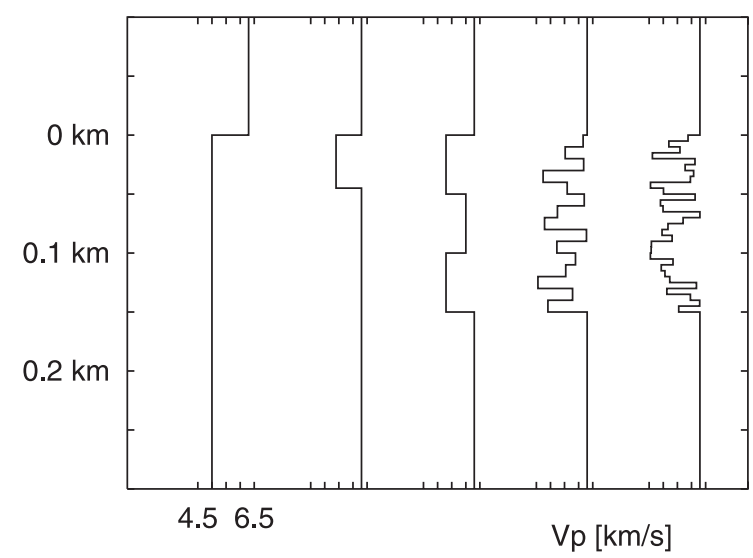

EB reflector models

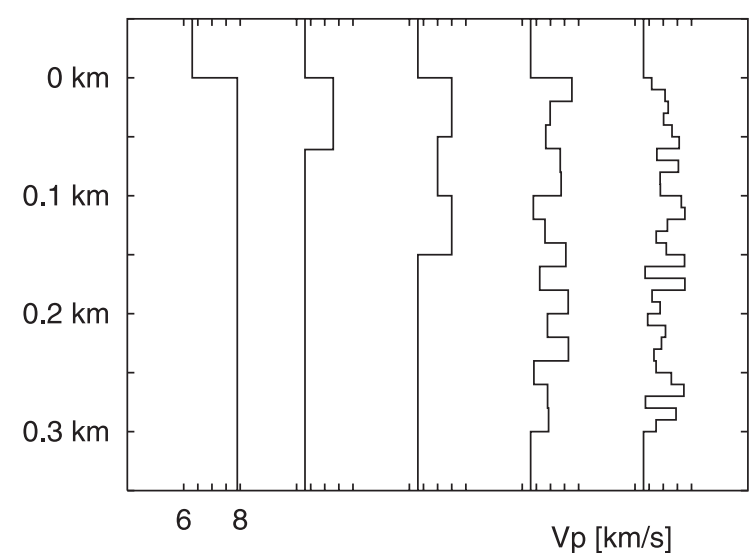

SE1 seismograms shot 18615

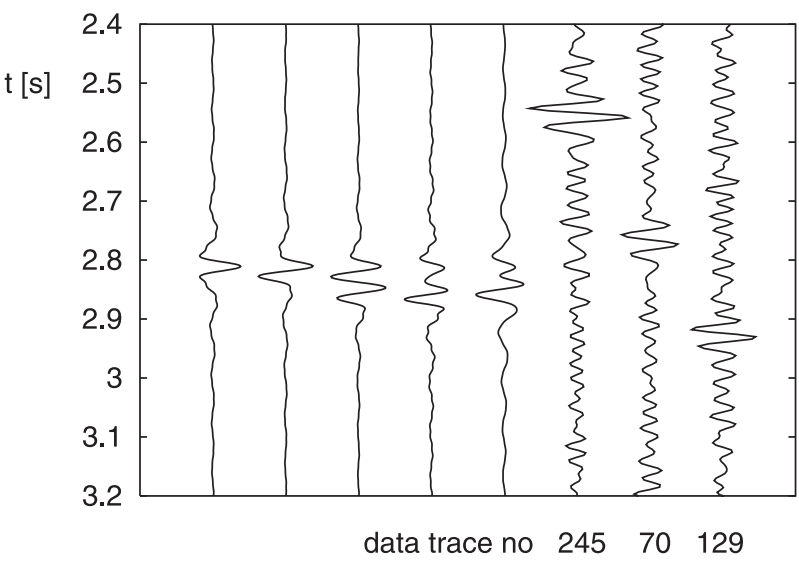

EB seismograms

shot 17642

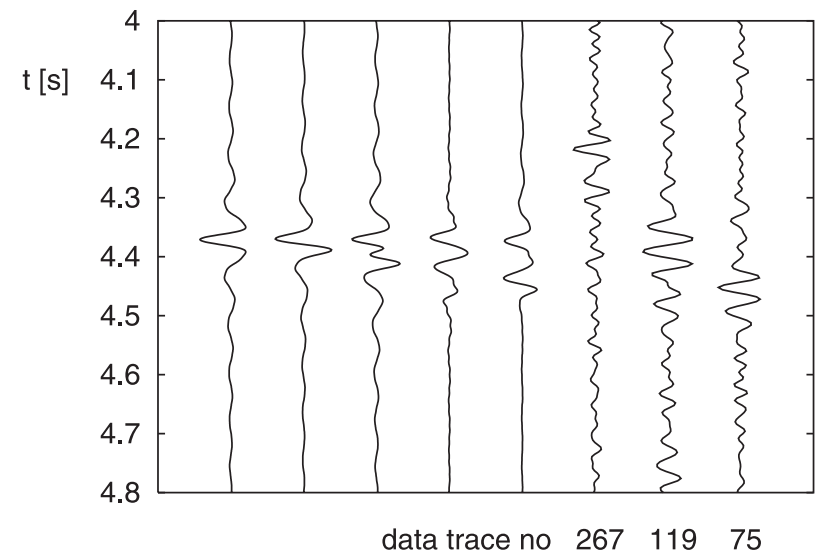

Figure 10. (left) The 1-D velocity-depth models and (right) corresponding synthetic seismograms which approximately match the observed amplitudes for the SE1 and EB reflections. Depth is perpendicular to the reflectors. From left to right in each panel are shown a first-order discontinuity, a $\lambda / 4$ layer, a zone with alternating high- and low-velocity layers, two examples of zones with a quasi-statistical velocity-depth distribution, determined with the aid of random numbers, data traces of shot locations 18615 and 17642. The synthetics are calculated with $Q_{p}=500$ for $z>1 \mathrm{~km}$; they are plotted on the same amplitude scale. 
the EB top to lower values inside would be compatible with the interpretation of the wide-angle measurements (a highvelocity layer of $2-3 \mathrm{~km}$ thickness on top of rocks with more normal crustal velocities).

[28] The reflector-zone model for both the SE1 and the EB part R1 must have pronounced parameter contrasts in order to explain the observed amplitude ratios with the $P_{g}$ reference phase (Figure 9). Velocity changes from 6.3 to an average velocity of $5.4 \mathrm{~km} / \mathrm{s}$ at the SE1 ( $\lambda / 4$ layers in Table 3 ) imply, with corresponding density changes, a normal-incidence $P$ wave reflection coefficient of -0.10 . The coefficient for the $\mathrm{EB}$ is +0.11 (6.3 to $7.4 \mathrm{~km} / \mathrm{s}$ velocity change; $\lambda / 4$ layers in Table 3). Note that in both zones reflection coefficients with opposite signs must occur. Constructive interference of the individual reflections is necessary to produce a composite reflection with the observed strength.

[29] In the case of the EB there are also less reflecting parts than R1. On parts B, G and R10 (Figure 8) velocity steps of only $0.5 \mathrm{~km} / \mathrm{s}$ are observed, from 6.3 to $6.8 \mathrm{~km} / \mathrm{s}$ for the firstorder discontinuity models in Table $3\left(Q_{p}=500\right)$. The strong change in the inferred reflector strength from R1 to the closest B spot on the EB (Figure 8) appears to be real: these spots are further apart than the diameter of the Fresnel zone ( $\sim 2 \mathrm{~km}$, for wavelength $0.25 \mathrm{~km}$ and path length $20 \mathrm{~km}$ ).

[30] The velocity variations in the successful SE1 models (Figure 10) are roughly equal in size to the variations in the smoothed acoustic log of the KTB main borehole and in the VSP interval-velocity distribution [Rabbel et al., 2000]. Yet the SE1 structure is much more localized in-depth. One reason for the difference could be that the SE1 reflector in the main borehole has weak parameter contrasts. Note that the SE1 reflection from the KTB intersection could have been observed with the shot-receiver configurations used, but the actual reflection points in Figure 8 are located at least $3 \mathrm{~km}$ south of the KTB location, and the KTB intersection is non-reflecting.

[31] As geological-petrological structures, the SE1 and the EB are known from previous studies to be much more extended than the identified reflection areas in Figure 8. The shot-reflector-receiver geometry used here provided illumination of larger areas, but most reflection coefficients were not strong enough to be observed. Mainly the areas of the strongest velocity and density contrasts and reflection coefficients were included in this study. Thus there is pronounced lateral variation of reflector strength.

[32] The SE1 results of this study quantitatively support the established view that it is a cataclastic thrust-fault zone which continues the Franconian Lineament into the crust [e.g., Zulauf and Duyster, 1997]. Because the fault at the surface separates mesozoic sediments and crystalline rocks, there is no outcrop evidence for the cataclastic properties of the fault within the basement. The evidence comes only from the SE1 reflections and, to some extent, from the KTB borehole observations. The lateral displacements along the fault in tectonically active times, which took place in a medium with natural velocity and density fluctuations, partly amplify and partly weaken the cataclastic effects and, hence, contribute to the variability of reflector strength.

[33] The EB reflector results of this study have been connected with the evidence from wide-angle seismics, that at about the same depths a high-velocity body starts [DEKORP Research Group, 1988; Gebrande et al., 1989].
In conclusion, this body has a cataclastic top zone with a thickness of a few hundred meters. Such a zone could possibly be the result of sill-like intrusion of the highvelocity body into the crust.

\section{Appendix A: $Q_{p}$ From Vertical Seismic Profiling at KTB}

[34] The purpose of this appendix is to illustrate the problems of determining a representative quality factor $Q_{p}$ from the VSP measurements in the KTB main borehole. $L i$ [1995] and Pujol et al. [1998] have derived $Q_{p}$ values as low as 20-50 from these data in the frequency range $20-30 \mathrm{~Hz}$ which approximately coincides with the dominant frequencies of the ISO-89 3D data studied here. For

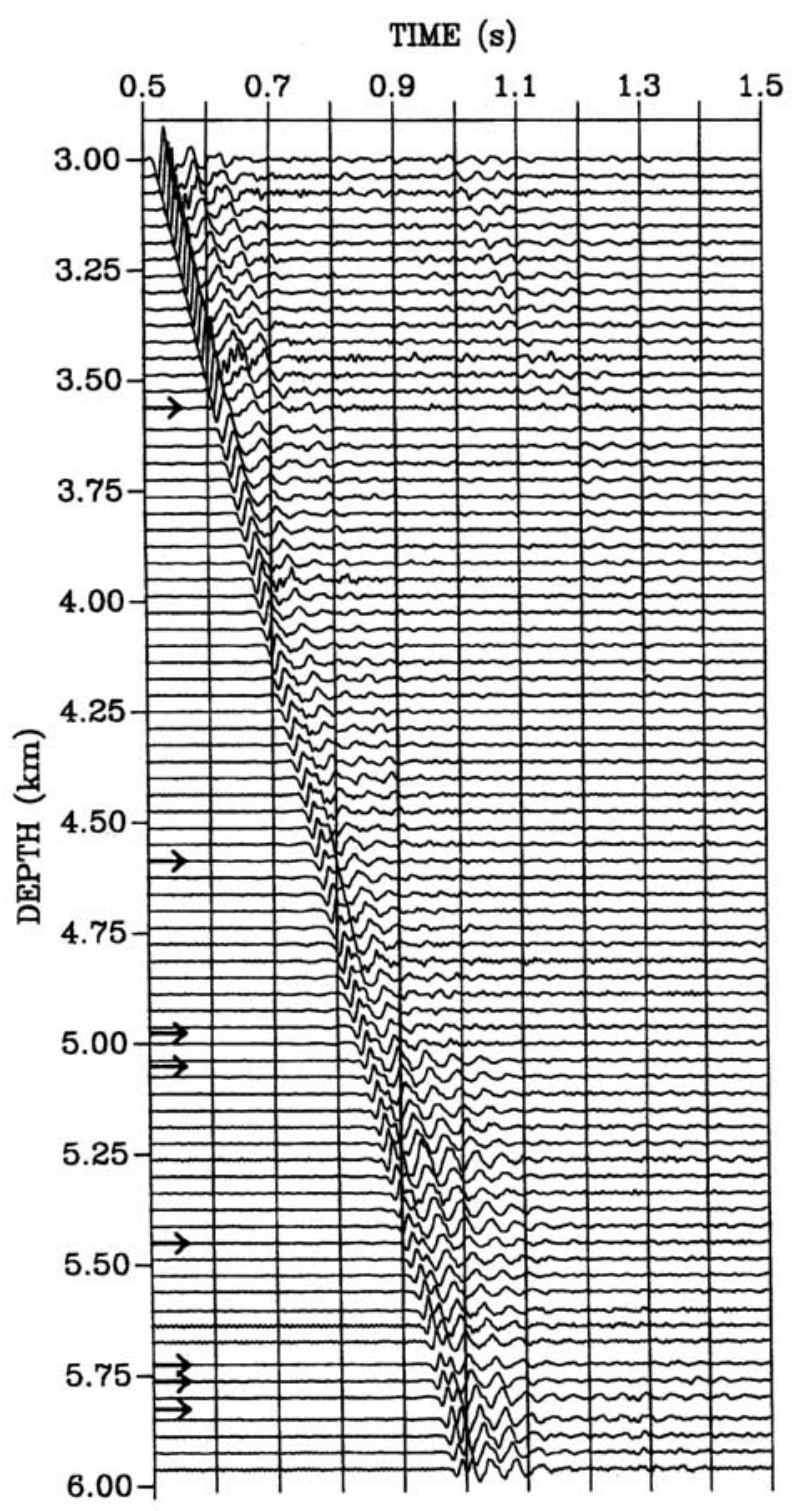

Figure A1. Vertical-seismic profiling seismograms, recorded in the main borehole of the KTB site and corrected for geometrical spreading. Figure from Pujol et al. [1998], reproduced with permission of the Society of Exploration Geophysicists, Tulsa, Oklahoma. 


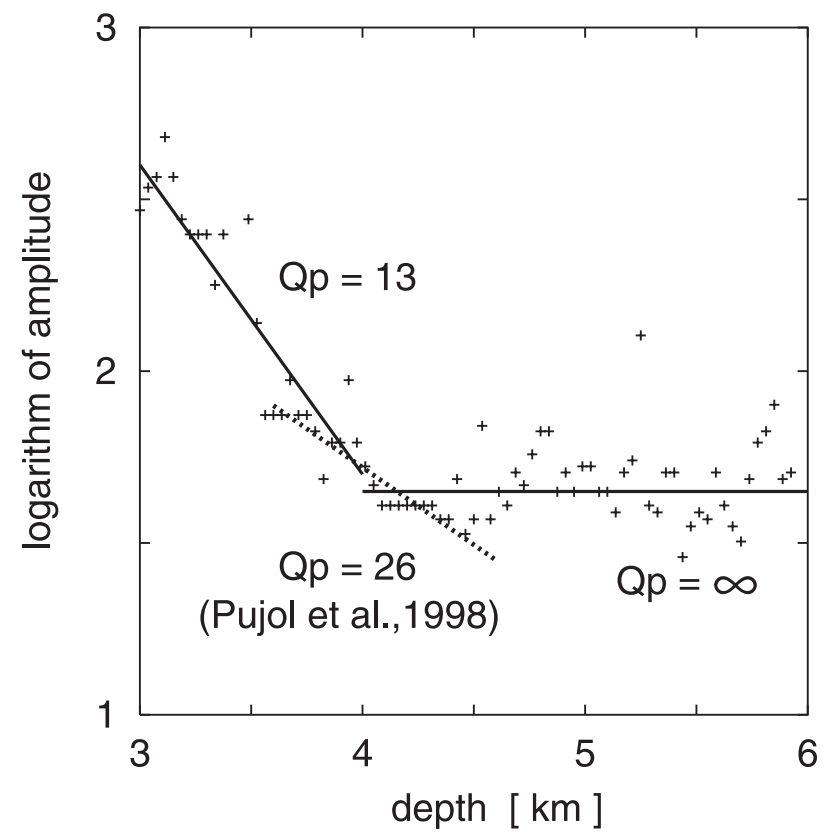

Figure A2. Maximum peak-to-peak amplitudes from Figure A1 and theoretical decay curves for different $Q_{p}$ values.

$Q_{p}=30$, a frequency of $25 \mathrm{~Hz}$ and a propagation distance of $10 \mathrm{~km}$ (roughly the one-way distance of the SE1 and EB reflectors from the vibrator locations), the exponential attenuation factor would be 0.013 , almost two orders of magnitude lower than the attenuation factor for the more conventional values $Q_{p}=500$ or 1000 ( 0.78 or 0.88 ). Crustal reflection seismology would virtually be impossible, if $Q_{p}$ of the order of 30 would characterize larger parts of the upper crust.

[35] In the present study very low $Q_{p}$ values are used to depths of $1 \mathrm{~km}$ to explain the partly strong amplitude decay of $P_{g}$ (see section 2 and Table 2). Such values probably characterize the eroded, fractured and jointed top of the crystalline basement, but it is unlikely that such pronounced heterogeneities extend to greater depths. Ryberg and Fuis [1998] provide evidence along the same lines for a reflection profile in southern California.

[36] Looking into the VSP data from which $\mathrm{Li}$ [1995] and Pujol et al. [1998] derived their $Q_{p}$ values, one can find highly variable $Q_{p}$, including $Q_{p}=\infty$. Figure A1 is taken from Pujol et al. [1998] and reproduces the VSP seismograms in the KTB main borehole at depths from 3 to $6 \mathrm{~km}$, corrected for geometrical spreading. In Figure A2 the maximum peak-to-peak amplitudes in the first $0.2 \mathrm{~s}$ of the direct wave are displayed as a function of depth. Between 3 and $4 \mathrm{~km}$, there is a general decay of the amplitudes, followed by rather constant amplitudes in the interval 4-6 km. Between 3 and $4 \mathrm{~km}$, the amplitudes correspond to the first oscillations, whereas between 4 and $6 \mathrm{~km}$ the peak-to-peak amplitudes partly are from later cycles. These time domain measurements are an alternative to the spectral measurements of Pujol et al. [1998], but with a very different result, namely $Q_{p}=13$ between 3 and $4 \mathrm{~km}$ and $Q_{p}=\infty$ between 4 and $6 \mathrm{~km}$. The depth range that was used by Pujol et al. [1998] and their result $Q_{p}=26$ (for $23.4 \mathrm{~Hz}$ ) are also indicated in Figure A2. In conclusion, the $Q_{p}$ values depend strongly on the depth range considered and to some extent also on the method of analysis. Moreover, VSP measurements are particularly difficult to correct for geometrical spreading close to the source where the elastic effects on amplitudes are more variable than far away, and systematic $Q_{p}$ errors are likely. Therefore, the VSP measurements in the KTB main borehole do not allow safe inferences on $Q_{p}$ for larger crustal volumes. It is much safer to rely on earthquake and explosion studies in different parts of the world which point to crustal $Q_{p}$ values of several hundred (see citations in section 4).

[37] The amplitude interpretations of the SE1 and EB reflections for this paper were, therefore, performed with more conventional $Q_{p}$ values $(\infty, 500,250)$ with a preference for $Q_{p}=500$. They imply a relatively small influence of attenuation on the reflections. Even then, as shown in section 4, noticeable reflection coefficients are obtained; for $Q_{p}$ much less than 500 they would be larger than 1 which is physical impossible.

[38] Acknowledgments. This work was supported by Deutsche Forschungsgemeinschaft (grant $\mathrm{Mu} 421 / 25$ ). The authors are grateful to W. Rabbel (University of Kiel) for providing VSP interval velocities, to C. Trela (Geoforschungszentrum Potsdam) for discussions on $Q$ factors at the KTB area, to H. Winter (University of Munich) for detailed remarks on the KTB borehole logs and their evidence for the depth of the SE1 reflector, and to U. Polom (Technical University of Clausthal) for discussions on noise in vibroseis data. Thanks go also to C. Juhlin, an anonymous reviewer, and D. Snyder (Associate Editor) for critical and helpful reviews.

\section{References}

Adams, D. A., and R. E. Abercrombie, Seismic attenuation above $10 \mathrm{~Hz}$ in southern California from coda waves recorded in the Cajon Pass borehole, J. Geophys. Res., 103, 24,257-24,270, 1998.

Aster, R. C., and P. M. Shearer, High frequency borehole seismograms recorded in the San Jacinto fault zone, southern California, part 2, Attenuation and site effects, Bull. Seismol. Soc. Am., 81, 1081-1100, 1991.

Benz, H. M., A. Frankel, and D. M. Boore, Regional $L_{g}$ Attenuation for the Continental United States, Bull. Seismol. Soc. Am., 87, 606-619, 1997.

Bram, K., and J. K. Draxler (Eds.), Basic research and borehole geophysics (final report), KTB Rep. 94-1, Annexe, Niedersächsisches Landesamt für Bodenforschung, Hannover, Germany, 1995.

Buske, S., Three-dimensional pre-stack Kirchhoff migration of deep seismic reflection data, Geophys. J. Int., 137, 243-260, 1999.

Carr, B. J., S. B. Smithson, N. Kareav, A. Ronin, V. Garipov, Y. Kristoffersen, P. Diagranes, D. Smythe, and C. Gillen, Vertical seismic profile results from the Kola Superdeep Borehole, Russia, Tectonophysics, 264, 205-307, 1996.

Cervený, V., and R. Ravindra, Theory of Seismic Head Waves, 312 pp., Univ. of Toronto Press, Toronto, Ont., 1971.

Cervený, V., I. A. Molotkov, and I. Pšenčík, Ray Method in Seismology, 214 pp., Univ. Karlova, Prague, 1977.

DEKORP Research Group, Results of the DEKORP 4/KTB Oberpfalz deep seismic reflection investigations, J. Geophys., 62, 69-101, 1988.

Dürbaum, H.-J. C. Reichert, and K. Bram (Eds.), Integrated seismics Oberpfalz 1989: Longterm logging and testing programme of the KTBOberpfalz VB, KTB Rep. 90-6b, 208 pp., Niedersächsisches Landesamt für Bodenforschung, Hannover, Germany, 1990.

Dürbaum, H.-J. C. Reichert, P. Sadowiak, and K. Bram (Eds.), Integrated seismics Oberpfalz 1989: Data evaluation and interpretation as of October 1992, KTB Rep. 92-5, 373 pp., Niedersächsisches Landesamt für Bodenforschung, Hannover, Germany, 1992.

Fletcher, J. B., T. Fumal, H.-P. Liu, and L. C. Carroll, Near surface velocities and attenuation at two boreholes near Anza, California, from logging data, Bull. Seismol. Soc. Am., 80, 807-831, 1990.

Ganchin, Y. V., S. B. Smithson, I. B. Morozov, D. K. Smythe, V. Z. Garipov, N. A. Kareav, and Y. Kristoffersen, Seismic studies around the Kola Superdeep Borehole, Russia, Tectonophysics, 288, 1-16, 1998.

Gebrande, H., M. Bopp, and T. Schmidt, Crustal structure in the surround- 
ings of the KTB drill site as derived from refraction and wide-angle seismic observations, in The German Continental Deep Drilling Program. edited by R. Emmermann and J. Wohlenberg, pp. 151-176, Springer-Verlag, New York, 1989.

Grad, M., and U. Luosto, Seismic velocities and Q-factors in the uppermost crust beneath the SVEKA profile in Finland, Tectonophysics, 230, 1-18, 1994.

Grant, F. S., G. F. West, Interpretation Theory in Applied Geophysics, 583 pp., McGraw-Hill, New York, 1965.

Harjes, H.-P., and M. Janik, Origin of reflections from the Altenparkstein fault zone (KTB), KTB Rep. 94-2, A97-A106, Niedersächsisches Landesamt für Bodenforschung, Hannover, Germany, 1994.

Harjes, H.-P., et al., Origin and nature of crustal reflections: Results from integrated seismic measurements at the KTB superdeep drilling site, J. Geophys. Res., 102, 18,267-18,288, 1997.

Havskov, J., and J. Medhus, $Q$ along the FENNOLORA profile, Geophys. J. Int., 106, 531-536, 1991.

Juhlin, C., Interpretation of reflections in the Siljan Ring area based on results from the Gravberg-1 borehole, Tectonophysics, 173, 345-360, 1990.

Juhlin, C., M. Bliznetsov, L. Pevzner, T. Hismatulin, A. Rybalka, and A. Glushkov, Seismic imaging of reflectors in the SG4 borehole, Middle Urals, Russia, Tectonophysics, 276, 1-18, 1997.

Körbe, M., M. Stiller, H. Horstmeyer, and T. Rühl, Migration of the 3-D deep-seismic reflection survey at the KTB location, Oberpfalz, Germany, Tectonophysics, 271, 135-156, 1997.

Kvamme, L. B., and J. Havskov, $Q$ in southern Norway, Bull. Seismol. Soc. Am., 79, 1575-1588, 1989.

Li, X.-P., Estimation of apparent seismic attenuation of crystalline rocks, Sci. Drill., 5, 199-216, 1995.

Officer, C. B., Introduction to the Theory of Sound Transmission, 284 pp., McGraw-Hill, New York, 1958.

Oye, V., True amplitudes of seismic-reflection data and migration, Diploma thesis, Johann Wolfgang Goethe-Univ, Frankfurt am Main, Frankfurt, Germany, 2000.

Petzold, L. R., Automatic selection of methods for solving stiff and nonstiff systems of ordinary differential equations, SIAM J. Stat. Comput., 4, $136-148,1983$.

Pujol, J. M., E. Lüschen, and Y. Hu, Seismic wave attenuation in metamorphic rocks from VSP data recorded in Germany's continental superdeep borehole, Geophysics, 63, 354-365, 1998.

Rabbel, W., et al., Vertical seismic profiling to depths of $8550 \mathrm{~m}$ in the main KTB borehole, paper presented at ICDP/KTB Colloquium, Ruhr Univ., Bochum, Germany, 15-16 June 2000.
Ryberg, T., and G. S. Fuis, The San-Gabriel Mountains bright reflective zone: possible evidence of young mid-crustal faulting in southern California, Tectonophysics, 286, 31-46, 1998.

Scheirer, D. S., and R. W. Hobbs, Seismic attenuation in the continental crust SW of England, Geophys. J. Int., 103, 533-540, 1990.

Schneider, W. A., Integral formulation for migration in two and three dimensions, Geophysics, 43, 49-76, 1978.

Seriff, A. J., and W. H. Kim, The effect of harmonic distortion in the use of vibratory surface sources, Geophysics, 35, 234-246, 1970.

Sheriff, R. E., and L. P. Geldart, Exploration Seismology, 592 pp., 2nd ed., Cambridge Univ. Press, New York, 1995.

Simon, M., AVO analysis by offset-limited prestack migrations of crustal seismic data, Tectonophysics, 286, 143-153, 1998.

Simon, M., H. Gebrande, and M. Bopp, Pre-stack migration and true-amplitude processing of DEKORP near-normal incidence and wide-angle reflection measurements, Tectonophysics, 264, 381-392, 1996.

Stiller, M., 3-D vertical incidence seismic reflection survey at the KTB location, Oberpfalz, in Continental Lithosphere: Deep Seismic Reflections, Geodyn. Ser, vol. 22, edited by R. Meissner et al., pp. 101-113, AGU, Washington, D.C., 1991.

Stiller, M., Preliminary generation of a stacked data volume of the entire ISO 89-3D data set using an envelope technique, KTB Rep. 92-5, pp. $3-$ 29, Niedersächsisches Landesamt für Bodenforschung, Hannover, Germany, 1992.

Wiederhold, H., Interpretation of envelope-stacked 3D seismic data and its migration-Another approach, KTB Rep. 92-5, pp. 67-113, Niedersächsisches Landesamt für Bodenforschung, Hannover, Germany, 1992.

Zulauf, G., and J. Duyster, Supracrustal intraplate thickening of Variscan basement due to Alpine foreland compression: Results from the superdeep well KTB (Bohemian Massif Germany), Tectonics, 16, 730-743, 1997.

G. Müller, Institute of Meteorology and Geophysics, J.W. Goethe University, Feldbergstr. 47, D-60323 Frankfurt am Main, Germany. (gmueller@geophysik.uni-frankfurt.de)

M. Stiller, Geoforschungszentrum Potsdam, Telegrafenberg, D-14473 Potsdam, Germany. (manfred@gfz-potsdam.de)

M. Zillmer, GEOMAR Research Center for Marine Geosciences, Wischhofstr. 1-3, D-24148 Kiel, Germany. (mzillmer@geomar.de) 